\title{
Early genomic prediction of daughter pregnancy rate is associated with improved reproductive performance in Holstein dairy cows
}

\author{
F. S. Lima, ${ }^{1 *} \dagger \odot$ F. T. Silvestre,${ }^{2}$ F. Peñagaricano,,${ }^{3,4} \odot$ and W. W. Thatcher ${ }^{3} \oplus$ \\ ${ }^{1}$ Department of Veterinary Clinical Medicine, University of Illinois, Urbana 61802 \\ ${ }^{2}$ Zoetis Inc., Kalamazoo, MI 49007 \\ ${ }^{3}$ Department of Animal Sciences, University of Florida, Gainesville 32611 \\ ${ }^{4}$ University of Florida Genetics Institute, University of Florida, Gainesville 32611
}

\begin{abstract}
The use of genomic testing for selecting replacement heifers in commercial farms has recently attracted much attention. Fertility traits are among the most complex, hard to measure, and lowly heritable traits, and hence they can benefit the most from genomic testing. The objectives of this study were to assess the relationship between early genomic prediction of daughter pregnancy rate (GDPR) and pregnancy at the first service (P1), pregnancy at the end of lactation (PEND), number of services for conception (NSFC), days from calving to first service (TP1), and days open (TPEND). Data for GDPR, milk production, and reproductive outcomes from 1,401 multiparous and 3,044 primiparous Holstein cows from 4 commercial farms with the same reproductive management were used in the analyses. All animals were genotyped and genomically evaluated as heifers before first breeding, so no phenotypic data were available for predicting genomic merits. In addition, all animals were genotyped and evaluated as heifers before first breeding, so no phenotypic data were available for prediction. Data for GDPR and milk production were categorized in quartiles. The statistical models included GDPR, farm-year-season of the first insemination, milk yield, breeding code (estrus detection or timed artificial insemination), and the interaction terms as potential predictors for the different reproductive outcomes evaluated. Data were analyzed separately for primiparous and multiparous cows. The proportion of cows bred by estrus detection increased linearly from lowest to highest GDPR in primiparous cows. There were positive associations of GDPR for P1, PEND, NSFC, TP1, and TPEND in both primiparous and multiparous cows. For instance, positive GDPR
\end{abstract}

Received August 22, 2019.

Accepted December 20, 2019.

*Corresponding author: falima@ucdavis.edu

†Current address: Department of Population Health and Reproduction, School of Veterinary Medicine, University of California, Davis 95616. effects in multiparous cows included a $15.7 \%$ higher P1 (47.6\% vs. $31.9 \%), 11.9 \%$ higher PEND ( $84.9 \%$ vs. $73.0 \%$ ), and 48.0-d shorter TPEND (139.8 vs. $175.7 \mathrm{~d}$ ) for the highest quartile compared with the lowest quartile. Milk yield affected PEND in multiparous cows, and TPEND and NSFC affected PEND in primiparous cows. The only significant interaction between GDPR and milk production was detected for NSFC in primiparous cows, where high-producing cows showed a reduction in NSFC as GDPR increased, whereas lowproducing cows showed no relationship between GDPR and NSFC. Overall, our findings show that GDPR can be effectively used as a predictor of future reproductive performance, reaffirming the potential benefits of applying early genomic predictions for making accurate early selection decisions.

Key words: genomic testing, daughter pregnancy rate, reproductive performance

\section{INTRODUCTION}

Phenotypic and genetic trends for milk production and daughter pregnancy rate (DPR) in US Holsteins moved in opposite directions between the early 1960s and early 2000s (Lucy, 2001; VanRaden et al., 2004). During those 4 decades, the breeding values for milk production for the Holstein population increased about $3,000 \mathrm{~kg}$. However, this success was accompanied by a decline in cow fertility, such that infertility became a major concern of farmers and the dairy industry (AIPL, 2005). Genetic evaluations for DPR were introduced in the United States in 2003 with the intent to mitigate the decline in fertility (VanRaden et al., 2004). The incorporation of DPR in the breeding programs, the development of timed AI protocols, and improvements in reproductive management, nutrition, and herd health reversed the phenotypic decline in fertility in the US Holstein population and increased the genetic trend in DPR (Norman et al., 2009; USDA, 2019).

Despite the reversed trend in reproductive performance, breeding values of DPR remain remarkably lower 
than in the 1960s (USDA, 2019). Daughter pregnancy rate is a measurement of the hazard of pregnancy after calving (pregnancy risk for 21-d interval cycles after the voluntary waiting period) of a bull's daughters compared with the concurrent population. An estimated increase of 1 point in DPR is expected to result in a reduction in the interval from calving to pregnancy of approximately $4 \mathrm{~d}$ (Norman et al., 2009). The heritability of DPR is usually less than 10\% (Averill et al., 2004; Pryce et al., 2004). Recent advancements in genomic tools offer new opportunities to use DPR as selection criteria to improve dairy cow fertility. Indeed, genomic prediction for DPR (GDPR) based on the incorporation of genomic information through genome-wide SNP arrays led to a gain in reliability of $17 \%$ (Wiggans et al., 2011). The benefit of genomics is the greatest for lowly heritable traits and traits that can be measured only late in life, such as fertility. Indeed, genomic selection in US Holstein cattle has doubled the annual rates of genetic gain for production traits but has increased from 3 -fold to 4 -fold for fitness traits, including female fertility (García-Ruiz et al., 2016).

A recent study evaluated the association between genomic merit for DPR and estrus characteristics measured by an automated device, revealing that heifers in the bottom quartile for DPR had reduced hazard of estrus within $7 \mathrm{~d}$ of the first $\mathrm{PGF}_{2 \alpha}$ treatment and shorter length of $\mathrm{PGF}_{2 \alpha}$-induced estruses than heifers in the top quartile (Veronese et al., 2019a). The study also revealed that DPR was positively associated with first service pregnancy per AI but not with second service pregnancy per AI, suggesting that the relationship between GDPR and measures of reproductive performance needs further investigation.

The assessment of the relationship between GDPR and farm phenotypic data for reproductive performance could reinforce the idea that this trait can be used for improving fertility without significantly compromising milk production (Berry et al., 2014). Here, we hypothesized that GDPR is positively associated with improved reproductive performance independent of milk production. Our aims were to assess the relationship between GDPR and pregnancy at the first service $(\mathbf{P} \mathbf{1})$, pregnancy at the end of lactation (PEND), number of services for conception (NSFC), days from calving to first service (TP1), and days open at the end of lactation (TPEND) in lactating Holstein dairy cows.

\section{MATERIALS AND METHODS}

\section{Animals, Housing, and Management}

The data used for the current study were collected from 4 commercial dairy farms located in south-central
San Joaquin Valley in California. Farms were identified as A, B, C, and D to maintain confidentiality. A total of 3,044 Holstein primiparous cows from the 4 farms (A, B, C, and D) and 1,401 Holstein multiparous cows from 3 farms (B, C, and D) were used to evaluate the association between GDPR and different reproductive outcomes. All animals were genotyped using SNP platforms commercially available in the United States (Clarifide, Zoetis, Parsippany, NJ) when heifers were of pre-breeding age (i.e., before first breeding) between 2010 and 2015. All animals were genomically evaluated using 50k SNP across the genome. Note that the genetic base for DPR changed in December 2014 using a correction factor equal to 0.20 . Therefore, in this study, the DPR of heifers tested in 2015 were readjusted (i.e., DPR + 0.20), so all the DPR values had the same genetic base and same meaning. The cows used in this study did not contribute phenotype data to the national evaluation (i.e., these cows were not included in the reference population to predict genomic breeding values). The GDPR values were obtained from the US national evaluation provided by the Animal Improvement Programs Laboratory-USDA when the animals were heifers. In all farms, cows were housed in freestall barns bedded with sand or dried manure solids and equipped with fans and sprinklers for evaporative cooling, and cows were milked 2 (farms A, B, and D) or 3 (farm C) times a day. In all farms, cows received a TMR to meet or exceed the nutrient requirements for a lactating Holstein cow producing 35 to $45 \mathrm{~kg}$ of milk/d with $3.5 \%$ fat and $3.2 \%$ true protein when DMI is 21 to $23 \mathrm{~kg} / \mathrm{d}$ (NRC, 2001). Diets were fed to cows located in a group pen and adjusted according to refusals in each group.

\section{Reproductive Management, Pregnancy Diagnoses, and Reproductive Outcomes}

Cows used in the current study were exposed to a similar reproductive management that included the use of the Presynch-Ovsynch program with insemination after estrus detection, starting after the second $\mathrm{PGF}_{2 \alpha}$ of the Presynch program. Briefly, all cows in the 4 farms received an intramuscular injection of $\mathrm{PGF}_{2 \alpha}$ [i.e., 25 $\mathrm{mg}$ of dinoprost tromethamine $-5 \mathrm{~mL}$ of Lutalyse i.m. (Zoetis Inc., Kalamazoo, MI), or $500 \mu \mathrm{g}$ of cloprostenol sodium - $2 \mathrm{~mL}$ of Estrumate i.m. (Merck Animal Health, Madison, NJ)] at either 36 DIM (farms C and D) or 46 DIM (farms A and B). A second intramuscular injection of $\mathrm{PGF}_{2 \alpha}$ was administered $14 \mathrm{~d}$ later. At the second injection of $\mathrm{PGF}_{2 \alpha}$, cows' tailheads were painted daily with chalk, and those identified in estrus received AI on the same morning. Cows not observed in estrus between 12 and $14 \mathrm{~d}$ of the second $\mathrm{PGF}_{2 \alpha}$ treatment 
were enrolled in the Ovsynch program. The protocol included an intramuscular injection of GnRH [i.e., $100 \mu \mathrm{g}$ of gonadorelin diacetate $-2 \mathrm{~mL}$ of Cystorelin i.m. (Merial Inc., Duluth, GA); $100 \mu \mathrm{g}$ of gonadorelin hydrochloride $-2 \mathrm{~mL}$ of Factrel i.m. (Zoetis Inc.); or $100 \mu \mathrm{g}$ of gonadorelin acetate $-2 \mathrm{~mL}$ of Fertagyl i.m. (Merck Animal Health)] followed by an intramuscular injection of $\mathrm{PGF}_{2 \alpha} 7 \mathrm{~d}$ later. A second intramuscular injection of $\mathrm{GnRH}$ was administered at 56 or $72 \mathrm{~h}$ after the $\mathrm{PGF}_{2 \alpha}$. In cows receiving $\mathrm{GnRH}$ at $56 \mathrm{~h}$, timed $\mathrm{AI}$ was performed $16 \mathrm{~h}$ later. Cows administered $\mathrm{GnRH}$ at $72 \mathrm{~h}$ received timed $\mathrm{AI}$ at $72 \mathrm{~h}$ (Cosynch). If cows were detected in estrus after the $\mathrm{PGF}_{2 \alpha}$ treatment of the Ovsynch protocol, then AI was performed the same day.

Pregnancy was diagnosed via transrectal palpation on d $35 \pm 3$ after AI. Presence of an amniotic vesicle and membrane slip was the criterion for determining pregnancy. Pregnant cows on d $35 \pm 3$ were re-examined for pregnancy via transrectal palpation 5 wk later (d 70 $\pm 3 \mathrm{~d}$ of pregnancy) to reconfirm pregnancy status. In all farms, cows were rebred when detected in estrus or after being diagnosed nonpregnant. Cows diagnosed nonpregnant were resynchronized with Ovsynch starting on the day of pregnancy diagnosis.

The reproductive responses evaluated included P1, TP1, NSFC, PEND, and TPEND. Traits P1 and PEND were binary variables, coded as 1 if the cow became pregnant and 0 otherwise. The variable NSFC was the number of services performed to obtain a pregnancy. The variable TP1 was the interval from calving to the first service, and TPEND was days from calving to pregnancy or end of lactation. Average milk production data were obtained for the first 2 test-day records and defined as M1. Additionally, 305-d mature-milk equivalent (ME305) was obtained. Data for reproductive outcomes and milk production were collected from the on-farm software (DairyComp, Valley Agriculture Software, Tulare, CA).

\section{Statistical Analyses}

All statistical analyses were conducted using $\mathrm{R}$ software version 3.4.3 (https://www.r-project.org/). The data for primiparous and multiparous cows were analyzed separately because multiparous cows were not available for farm A. The data for GDPR and milk production (M1 and ME305) were categorized according to quartiles across all cows and farms. The values for GDPR, M1, and ME305 were grouped in ascending order from lowest $(\mathbf{Q 1})$ to highest $(\mathbf{Q} 4)$ quartiles. The M1 was used in the models for P1 and TP1, whereas the ME305 was used in the models for NSFC, PEND, and TPEND. Traits P1 and PEND were analyzed using logistic regressions, NSFC was analyzed using Poisson regression, and TP1 and TPEND were analyzed using linear regressions. The season for the first service was categorized as cool (November-April) or warm (May-October), and to account for the variability due to year, season, and farm, a new variable denoted as farm-year-season (year-season within each farm) was created. All statistical models included the effects of GDPR, farm-year-season, milk yield, and the interaction between GDPR and milk yield. Correlation analyses were performed for genomic PTA for milk (GPTAM), GDPR, M1, and ME305. Differences with $P \leq 0.05$ were considered significant, and differences with $0.05<P \leq 0.10$ were considered tendencies. Interactions were considered significant when $P \leq 0.05$.

\section{RESULTS}

\section{Descriptive Statistics}

Farm A had only primiparous cows $(\mathrm{n}=1,748)$, whereas farms B, C, and D had 704, 127, and 465 primiparous cows and 134, 915, and 352 multiparous cows, respectively. Descriptive data about quartiles of GDPR, M1, and ME305 for primiparous and multiparous cows are presented in Table 1. Similarly, descriptive data for GDPR and milk production (M1 and ME305) for farms $\mathrm{A}, \mathrm{B}, \mathrm{C}$, and $\mathrm{D}$, according to parity, are presented in Table 2.

The correlation between GDPR and GPTAM was $-0.22(P<0.001 ;$ Figure $1 \mathrm{~A})$. The correlations between GDPR and actual milk yield were +0.07 between GDPR and M1 (Figure 1B) and -0.11 between GDPR and ME305 (Figure 1C). Correlations $(P<0.001)$ between GPTAM and M1 and ME305 were 0.18 (Figure 1D) and 0.38 (Figure 1E), respectively. As expected, the variable farm-year-season had a significant effect $(P<0.001)$ on all the reproductive outcomes evaluated-namely, P1, TP1, NSFC, PEND, and TPEND.

\section{Relationship Between Breeding Strategies and GDPR}

In primiparous cows, the proportion of cows bred by estrus detection increased (chi-squared test of independence, $P<0.001$ ) linearly from Q1 to Q4 for GDPR $(\mathrm{Q} 1=59.6 \% ; \mathrm{Q} 2=64.8 \% ; \mathrm{Q} 3=72.4 \%$; and $\mathrm{Q} 4=$ $75.5 \%)$. In multiparous cows, the proportion of cows bred by estrus detection did not differ (chi-squared test of independence, $P=0.65$ ) among GDPR quartiles (Q1 $=72.3 \%$; $\mathrm{Q} 2=71.1 \%$; $\mathrm{Q} 3=71.1 \%$; and $\mathrm{Q} 4=74.8 \%$. 
Table 1. Descriptive data representing the number of cows $(n)$, mean $( \pm \mathrm{SE})$, and range for genomic prediction of daughter pregnancy rate (GDPR), average milk production in the first 2 tests (M1), and 305-d mature-milk equivalent (ME305) for the lowest (Q1), second (Q2), third (Q3), and highest (Q4) quartiles of primiparous and multiparous cows

\begin{tabular}{|c|c|c|c|c|c|c|c|c|c|}
\hline Item & \multicolumn{3}{|c|}{ GDPR } & \multicolumn{3}{|c|}{$\mathrm{M} 1, \mathrm{~kg} / \mathrm{d}$} & \multicolumn{3}{|c|}{ ME305, kg } \\
\hline Q1 & 795 & $-1.21 \pm 0.02$ & -4.3 to -0.6 & 766 & $23.0 \pm 0.09$ & 8.6 to 27.7 & 762 & $10,188 \pm 32.9$ & 5,763 to 11,359 \\
\hline Q2 & 821 & $-0.12 \pm 0.02$ & -0.5 to 0.2 & 736 & $30.4 \pm 0.04$ & 28.2 to 32.7 & 760 & $12,192 \pm 11.9$ & 11,363 to 12,463 \\
\hline Q3 & 675 & $0.62 \pm 0.01$ & 0.3 to 1.0 & 761 & $35.7 \pm 0.04$ & 33.2 to 39.1 & 761 & $12,977 \pm 11.9$ & 12,468 to 13,559 \\
\hline Q4 & 753 & $2.05 \pm 0.03$ & 1.1 to 5.3 & 781 & $41.9 \pm 0.18$ & 39.5 to 53.6 & 761 & $14,695 \pm 33.9$ & 13,563 to 18,795 \\
\hline Q2 & 354 & $1.11 \pm 0.02$ & 0.6 to 1.6 & 366 & $31.0 \pm 0.14$ & 28.1 to 32.7 & 351 & $11,947 \pm 15.6$ & 11,368 to 12,463 \\
\hline Q3 & 346 & $2.19 \pm 0.02$ & 1.7 to 2.7 & 344 & $36.6 \pm 0.09$ & 33.2 to 39.1 & 350 & $12,969 \pm 15.7$ & 12,468 to 13,559 \\
\hline Q4 & 342 & $3.52 \pm 0.04$ & 2.8 to 6.6 & 337 & $45.8 \pm 0.14$ & 39.5 to 60.4 & 350 & $14,493 \pm 41.5$ & 13,563 to 17,527 \\
\hline
\end{tabular}

\section{Association Between GDPR and P1}

In primiparous cows, P1 was greater $(P<0.001)$ in higher GDPR quartiles (Q2, Q3, and Q4) than in the lowest GDPR quartile (Q1; Figure 2A; Table 3). There were no effects of milk production $(P=0.13)$ or interactions between GDPR and milk yield $(P=0.46)$ for P1 in primiparous cows. In multiparous cows, P1 increased linearly $(P=0.002)$ from the lowest to the highest GDPR quartile (Figure 2B; Table 3). No effect of milk production $(P=0.41)$ or interaction between GDPR and milk production $(P=0.33)$ was detected for P1 in multiparous cows.

\section{Association Between GDPR and TP1}

In primiparous cows, TP1 was shortest in GDPR Q4 and increased $(P<0.001)$ linearly from the top to the bottom GDPR quartile (Figure 3A; Table 3). There was no effect of milk production $(P=0.35)$, but there was a tendency for a significant interaction between
GDPR and milk production $(P=0.051)$, with cows with the lowest milk production (Q1) having increased TP1 in GDPR Q1 but no differences in milk production in GDPR Q2, Q3, and Q4. In multiparous cows, TP1 was significantly shorter $(P=0.02)$ in GDPR Q4 than in Q1 (Figure 3B; Table 2). There were no effects of milk production $(P=0.43)$ or an interaction between GDPR and milk production $(P=0.76)$ for TP1 in multiparous cows.

\section{Association Between GDPR and NSFC}

In primiparous cows, a significantly lower number of services per conception $(P<0.001)$ were observed in higher GDPR quartiles (Q2, Q3, Q4) than in the lowest quartile (Q1; Figure 4A; Table 3). There was also an effect of milk production $(P<0.001)$, with Q2 and Q3 having fewer NSFC than Q1 and Q4 (Figure 4A; Table $3)$. There was a significant interaction between GDPR and milk production $(P=0.05)$, with high-producing cows showing fewer NSFC as GDPR increased, whereas

Table 2. Descriptive data representing the number of cows $(\mathrm{n})$ and the mean $( \pm \mathrm{SE})$ and range for genomic prediction for daughter pregnancy rate (GDPR), average milk production in the first 2 monthly tests (M1), and 305-d mature-milk equivalent (ME305) for farms A, B, C, and D in multiparous and primiparous cows

\begin{tabular}{|c|c|c|c|c|c|c|c|}
\hline \multirow[b]{2}{*}{ Item } & \multirow[b]{2}{*}{$\mathrm{n}$} & \multicolumn{2}{|c|}{ GDPR } & \multicolumn{2}{|c|}{$\mathrm{M} 1, \mathrm{~kg} / \mathrm{d}$} & \multicolumn{2}{|c|}{ ME305, kg } \\
\hline & & Mean $( \pm \mathrm{SE})$ & Range & Mean $( \pm \mathrm{SE})$ & Range & Mean $( \pm \mathrm{SE})$ & Range \\
\hline Farm A & 1,748 & $-0.14 \pm 0.02$ & -3.2 to 2.7 & $29.4 \pm 0.14$ & 8.6 to 53.6 & $12,226 \pm 43.0$ & 5,764 to 18,437 \\
\hline Farm B & 704 & $1.08 \pm 0.05$ & -3.2 to 4.9 & $29.8 \pm 0.23$ & 11.4 to 45.4 & $12,590 \pm 81.6$ & 5,922 to 18,795 \\
\hline Farm C & 127 & $1.52 \pm 0.16$ & -3.7 to 4.9 & $28.4 \pm 0.50$ & 15 to 42.7 & $12,898 \pm 145.2$ & 9,504 to 18,572 \\
\hline Farm D & 465 & $0.41 \pm 0.07$ & -4.3 to 5.3 & $30.5 \pm 0.23$ & 10 to 52.7 & $12,446 \pm 64.5$ & 8,614 to 17,290 \\
\hline Farm B & 134 & $1.63 \pm 0.12$ & -2.5 to 5.1 & $42.9 \pm 0.32$ & 16.8 to 55.4 & $12,693 \pm 151.9$ & 7,900 to 17,445 \\
\hline Farm C & 915 & $1.85 \pm 0.05$ & -3.9 to 6.6 & $42.4 \pm 0.23$ & 20.0 to 60.4 & $12,704 \pm 45.1$ & 9,354 to 17,527 \\
\hline Farm D & 352 & $0.65 \pm 0.09$ & -3.9 to 5.4 & $42.0 \pm 0.32$ & 21.4 to 59.1 & $12,706 \pm 69.3$ & 9,272 to 17,018 \\
\hline
\end{tabular}



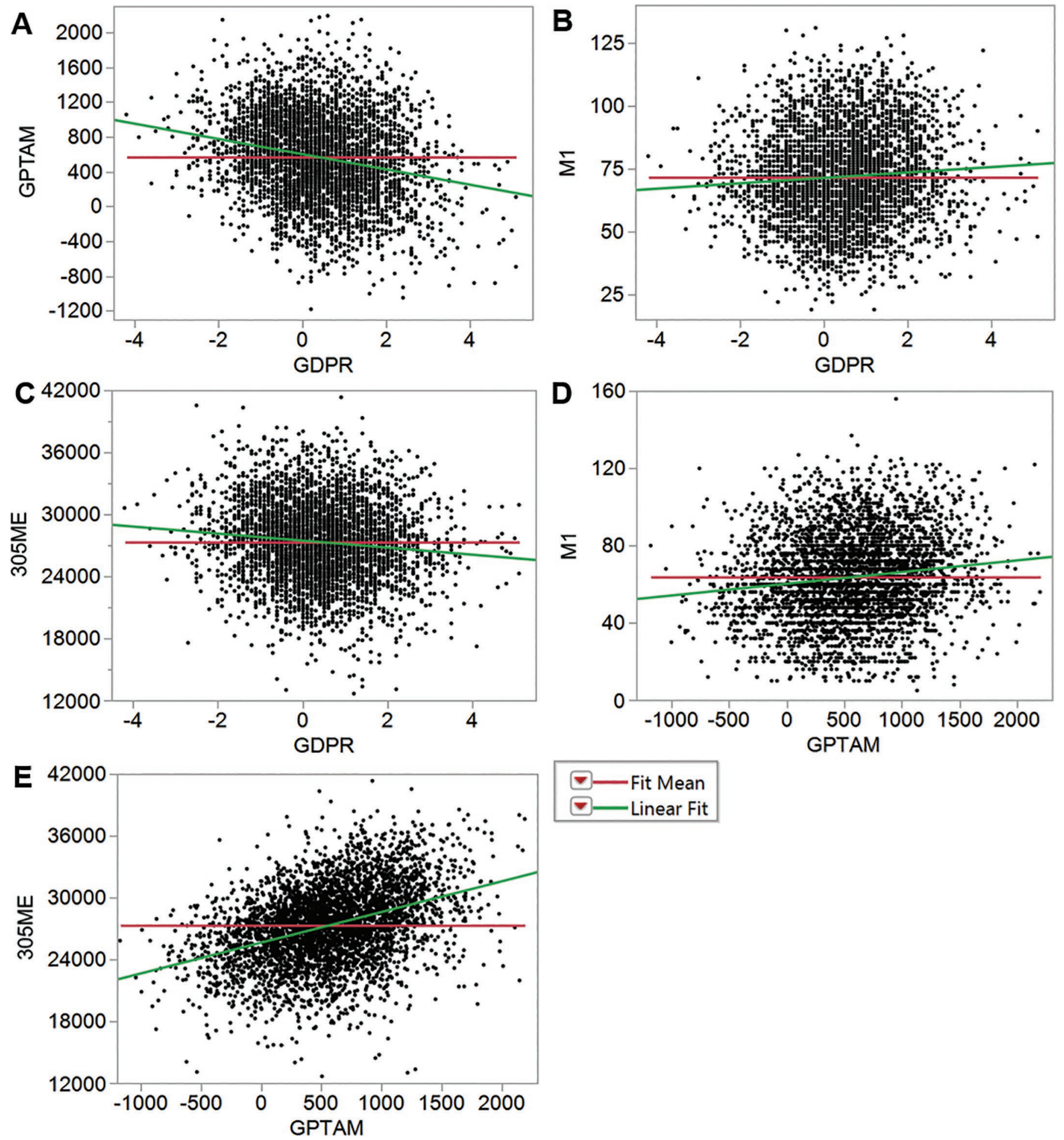

Figure 1. Scatter plots displaying (A) genomic PTA for milk (GPTAM) by genomic prediction for daughter pregnancy rate (GDPR), (B) average milk production for the first 2 mo of lactation (M1) by GDPR, (C) 305-d mature-milk equivalent (ME305) by GDPR, (D) M1 by GPTAM, and (E) ME305 by GPTAM. All correlations were statistically significant $(P<0.001)$. The correlations between GDPR and GPTAM, M1, and ME305 were $-0.22,0.07$, and -0.11 , respectively. The correlations between GPTAM and M1 and ME305 were 0.14 and 0.38 , respectively. 


\section{Milk Production Quartiles}

$\because \mathrm{Q} 1 \square \mathrm{Q} 2 \backsim \mathrm{Q} 3 \backsim \mathrm{Q} 4$

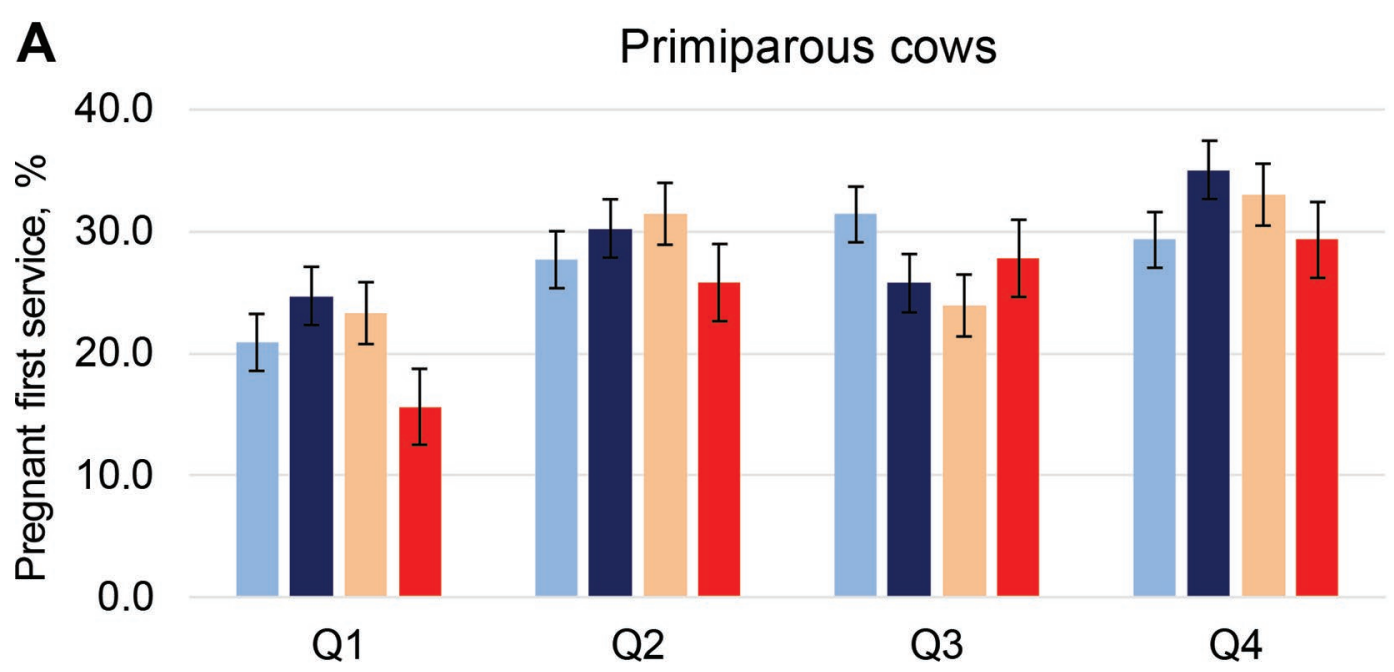

B

\section{Multiparous cows}

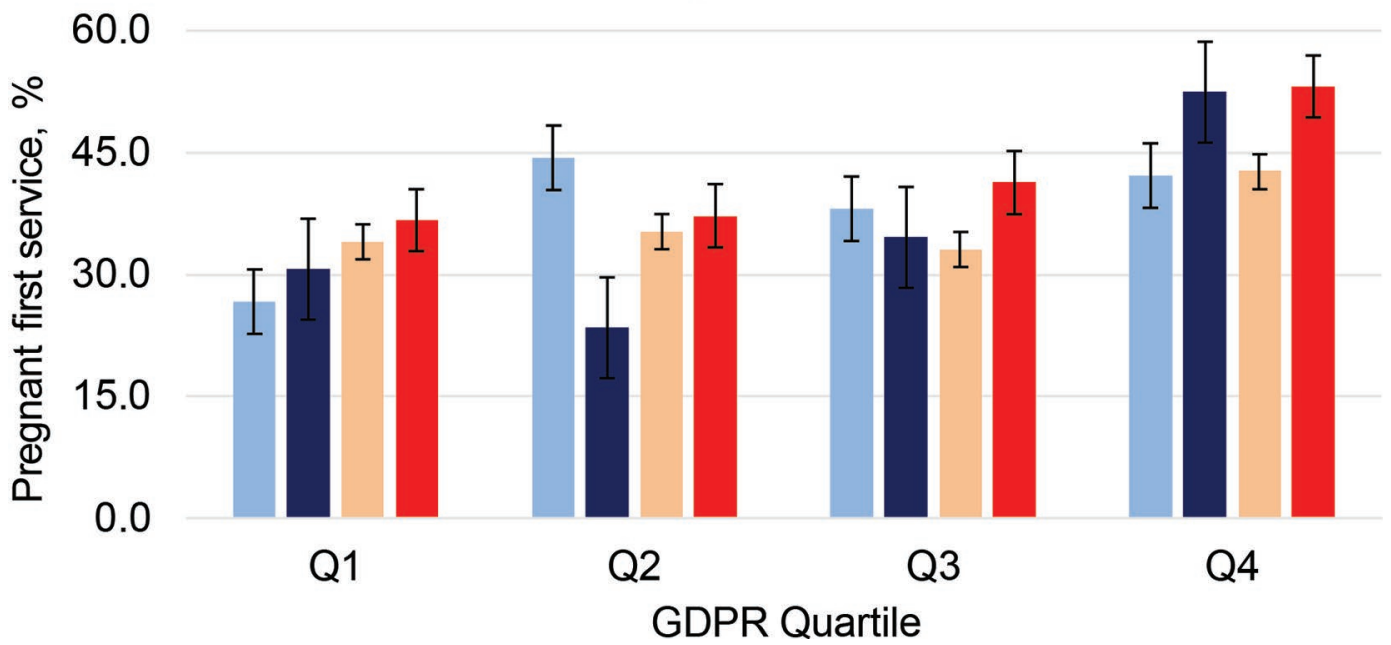

Figure 2. Bar charts displaying the percentage of pregnant cows for the first service according to quartiles $(\mathrm{Q} 1=$ lowest quartile; $\mathrm{Q} 4=$ highest quartile) for genomic prediction for daughter pregnancy rate (GDPR) and quartiles for average milk production for the first 2 mo of lactation (Q1 = lowest quartile; Q4 = highest quartile) in (A) primiparous cows and (B) multiparous cows. Pregnancy at the first service was greater in primiparous $(P<0.001)$ and multiparous $(P=0.002)$ cows in GDPR quartiles Q2, Q3, and Q4 than in Q1, but no differences for quartiles of milk production and the interactions of GDPR and milk production were found. Error bars represent SEM.

low-producing cows showed no relationship between GDPR and NSFC (Figure 4A). In multiparous cows, NSFC was significantly reduced $(P=0.01)$ in the highest GDPR quartile (Q4) than in GDPR Q1, Q2, and Q3 (Figure 4B; Table 3). There was no effect of milk production $(P=0.65)$ or an interaction between GDPR and milk production $(P=0.49)$ for NSFC in multiparous cows.

\section{Association Between GDPR and PEND}

In primiparous cows, PEND increased $(P<0.001)$ linearly from the lowest quartile to the highest quartile of GDPR (Figure 5A; Table 3). There was no effect $(P=0.61)$ of milk production on PEND (Figure 5A). There was no interaction between GDPR and milk production $(P=0.25)$ for PEND, indicating that the linear 
Table 3. Reproductive parameters for lowest (Q1), second (Q2), third (Q3), and highest (Q4) quartiles for genomic prediction for daughter pregnancy rate (GDPR) in multiparous and primiparous cows ${ }^{1}$

\begin{tabular}{|c|c|c|c|c|c|}
\hline \multirow[b]{2}{*}{ Item } & \multicolumn{4}{|c|}{ GDPR } & \multirow[b]{2}{*}{$P$-value } \\
\hline & Q1 & Q2 & Q3 & Q4 & \\
\hline \multicolumn{6}{|c|}{ Primiparous cows } \\
\hline $\mathrm{P} 1, \%$ & $20.9 \pm 1.7$ & $28.7 \pm 2.0$ & $28.3 \pm 2.1$ & $31.6 \pm 1.9$ & $<0.001$ \\
\hline $\mathrm{TP} 1, \mathrm{~d}$ & $72.9 \pm 0.5$ & $71.1 \pm 0.5$ & $70.4 \pm 0.6$ & $68.4 \pm 0.5$ & $<0.001$ \\
\hline NSFC, no. & $2.54 \pm 0.1$ & $2.29 \pm 0.1$ & $2.16 \pm 0.1$ & $2.11 \pm 0.1$ & $<0.001$ \\
\hline PEND, \% & $75.6 \pm 2.4$ & $80.6 \pm 2.1$ & $82.5 \pm 2.1$ & $85.0 \pm 1.8$ & $<0.001$ \\
\hline TPEND, d & $195.3 \pm 4.0$ & $180.4 \pm 3.9$ & $173.6 \pm 4.1$ & $165.2 \pm 3.7$ & $<0.001$ \\
\hline \multicolumn{6}{|c|}{ Multiparous cows } \\
\hline $\mathrm{P} 1, \%$ & $31.9 \pm 3.0$ & $34.6 \pm 3.2$ & $36.7 \pm 3.3$ & $47.6 \pm 3.8$ & 0.002 \\
\hline TP1, d & $66.5 \pm 0.6$ & $64.9 \pm 0.6$ & $64.5 \pm 0.7$ & $63.7 \pm 0.7$ & 0.02 \\
\hline NSFC, no. & $2.03 \pm 0.1$ & $1.93 \pm 0.1$ & $1.89 \pm 0.1$ & $1.69 \pm 0.1$ & 0.01 \\
\hline PEND, $\%$ & $73.0 \pm 3.1$ & $78.2 \pm 2.9$ & $82.4 \pm 2.7$ & $84.9 \pm 2.6$ & $<0.001$ \\
\hline TPEND, $\mathrm{d}$ & $175.7 \pm 5.9$ & $166.4 \pm 6.1$ & $150.7 \pm 6.3$ & $139.8 \pm 6.6$ & $<0.001$ \\
\hline
\end{tabular}

${ }^{1} \mathrm{P} 1=$ pregnancy at first insemination; TP1 $=$ time from calving to first insemination; NSFC $=$ number of services; PEND = pregnancy at the end of lactation; TPEND = time from calving to pregnancy at the end of lactation. Values are LSM \pm SEM.

PEND associated with GDPR was consistent across all 4 quartiles of milk production. In multiparous cows, PEND was significantly higher $(P=0.003)$ in GDPR Q3 and Q4 than in Q1 and Q2 (Figure 5B; Table 3). There was also an effect of milk yield $(P=0.03)$, with the lowest quartile (Q1) and the highest quartile (Q4) having higher PEND than the intermediate quartiles (Q2 and Q3; Figure 5B). There was no interaction between GDPR and milk production $(P=0.48)$ for PEND in multiparous cows.

\section{Association Between GDPR and TPEND}

In primiparous cows, TPEND decreased $(P<0.001)$ linearly from the lowest (Q1) to the highest (Q4) GDPR quartiles (Figure 6A; Table 3). There was an effect $(P$ $<0.001$ ) of milk production, with cows in Q4 having higher TPEND than cows in Q1, Q2, and Q3. There was no interaction between GDPR and milk production $(P=0.13)$ for TPEND in primiparous cows. In multiparous cows, TPEND also decreased $(P<0.001)$ from GDPR Q1 to GDPR Q4 (Figure 6B; Table 3). There was a tendency $(P=0.10)$ for milk production $\mathrm{Q} 1$ and Q4 to have shorter TPEND than Q2 and Q3. This pattern was consistent among GDPR quartiles, indicating no interaction between GDPR and milk production $(P$ $=0.76)$ for TPEND in multiparous cows.

\section{DISCUSSION}

The current study reaffirms that GDPR can be effectively used as a predictor of future reproductive performance in both primiparous and multiparous cows. The findings of the current study also confirmed that the environment, defined here as farm within year and sea- son of first breeding, is a significant factor contributing to reproductive performance and expression of genomic merit. The correlations between GDPR and either GPTAM or actual milk production were slightly negative. These correlations are similar to those reported in an earlier meta-analysis evaluating fertility and milk yield (Berry et al., 2014). Our results also revealed that type of breeding (AI after estrus detection or timed AI) did not affect reproductive performance, but the proportion of primiparous cows bred after estrus detection increased linearly with genetic merit for GDPR.

Although reproductive outcomes evaluated in this study are related, they offer specific insights on how GDPR might influence the fertility of dairy cows. For example, time for the first service could be improved only if the lactating dairy cows in this study responded to the second $\mathrm{PGF}_{2 \alpha}$ of the presynchronization program and showed evident signs of estrus behavior to be inseminated. In fact, a larger proportion of primiparous cows in higher GDPR quartiles was bred at estrus. In addition, there was a clear negative (favorable) relationship between TP1 and GDPR quartiles for both primiparous and multiparous cows. A recent study indicated that heifers in the highest GDPR quartile had a shorter interval to detected estruses induced by $\mathrm{PGF}_{2 \alpha}$, increased hazard of estrus $7 \mathrm{~d}$ after $\mathrm{PGF}_{2 \alpha}$, and lower rumination nadir compared with heifers in the lowest quartile (Veronese et al., 2019a). Other recent findings also indicated that heifers with high GDPR $(3.26 \pm 0.76)$ versus low GDPR $(-0.17 \pm 0.75)$ had increased concentrations of estradiol within $24 \mathrm{~h}$ of the $\mathrm{PGF}_{2 \alpha}$-induced estrus (4.53 \pm 0.23 vs. $3.79 \pm 0.23 \mathrm{pg} /$ $\mathrm{mL}$ ), suggesting that hormonal support for improving estrus behavior is present in high GDPR (Veronese et al., 2019b). In the current study, characteristics of 


\section{Milk Production Quartiles}

$\square \mathrm{Q} 1 \square \mathrm{Q} 2 \backsim \mathrm{Q} 3 \backsim \mathrm{Q} 4$

\section{A \\ Primiparous cows}

78
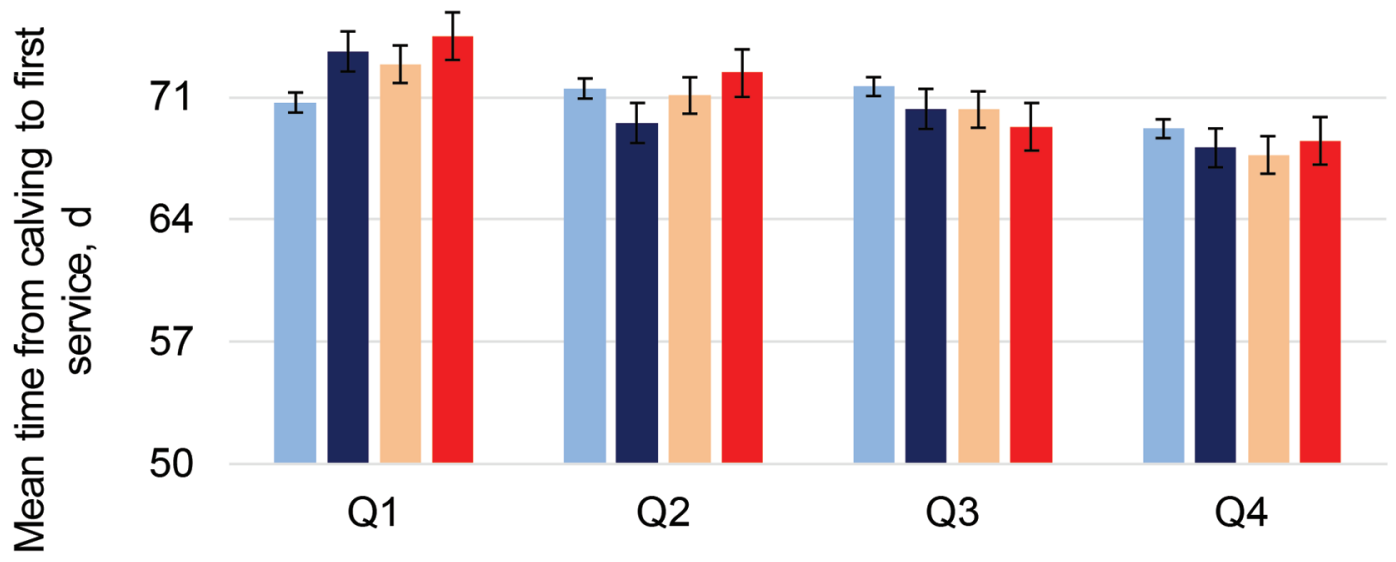

B

Multiparous cows

70

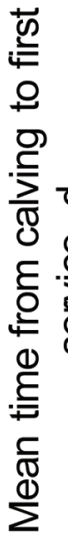

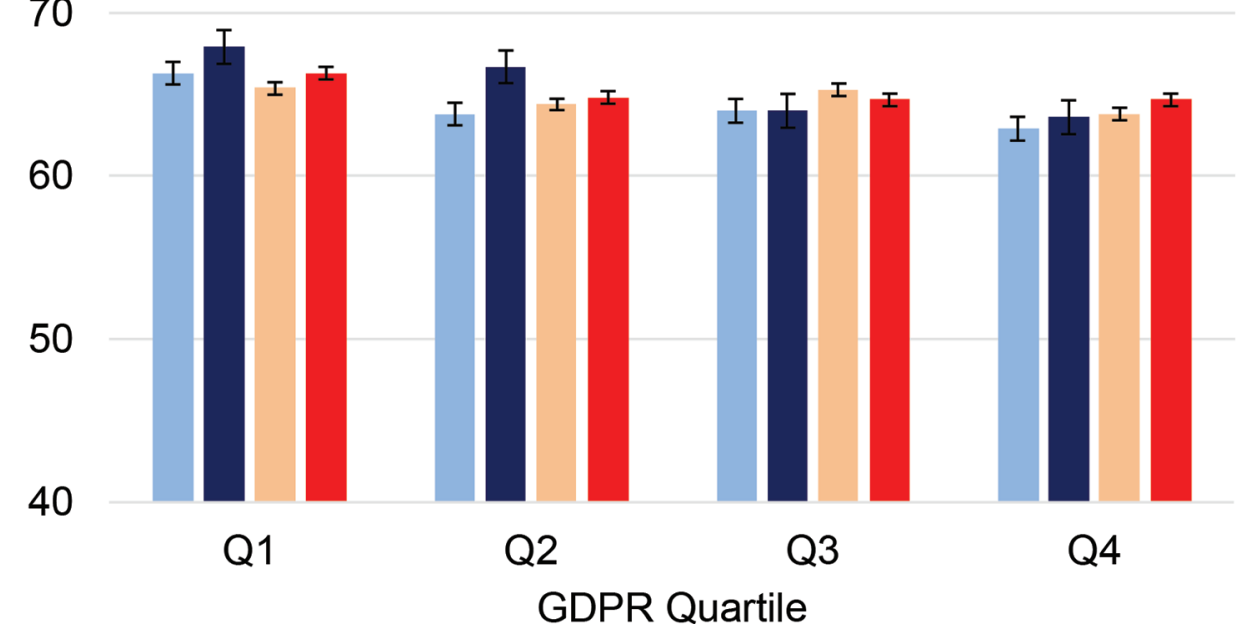

Figure 3. Bar charts displaying the mean time from calving to the first service according to quartiles (Q1 = lowest quartile; Q4 = highest quartile) for genomic prediction for daughter pregnancy rate (GDPR) and quartiles for average milk production for the first 2 mo of lactation (Q1 = lowest quartile; Q4 = highest quartile) in (A) primiparous cows and (B) multiparous cows. Mean time from calving to the first service was lower in primiparous $(P<0.001)$ and multiparous $(P=0.02)$ cows in GDRP quartiles Q1, Q2, and Q3 than in Q4, but no differences for quartiles of milk production and the interactions of GDPR and milk production for multiparous cows were found. There was a tendency for a significant interaction between GDPR and milk production $(P=0.051)$, with cows in the lowest milk production quartile (Q1) having increased days from calving to first service in GDPR Q1 but no differences in milk production and GDPR Q2, Q3, and Q4. Error bars represent SEM.

estrus and estradiol concentrations in plasma were not evaluated. The fact that primiparous and multiparous cows in the highest GDPR quartile had lower TP1 than cows in the lowest GDPR quartile implies that lactating cows might share similar mechanisms of improved estrus characteristics as in heifers. In the present study, the association between the proportion of cows bred at detected estrus and GDPR was positive in primiparous cows and not detected in multiparous cows. Overall, more multiparous cows than primiparous cows were bred after detected estrus. Primiparity has been reported to be a risk factor for the resumption of ovulation at $65 \mathrm{~d}$ postpartum (Santos et al., 2009). Potential explanations for the delayed estrous cyclicity in primiparous cows include an increased concentration of nonesterified fatty acids early postpartum (Wathes 


\section{Milk Production Quartiles \\ $\because \mathrm{Q} 1 \backsim \mathrm{Q} 2 \backsim \mathrm{Q} 3 \backsim \mathrm{Q} 4$}

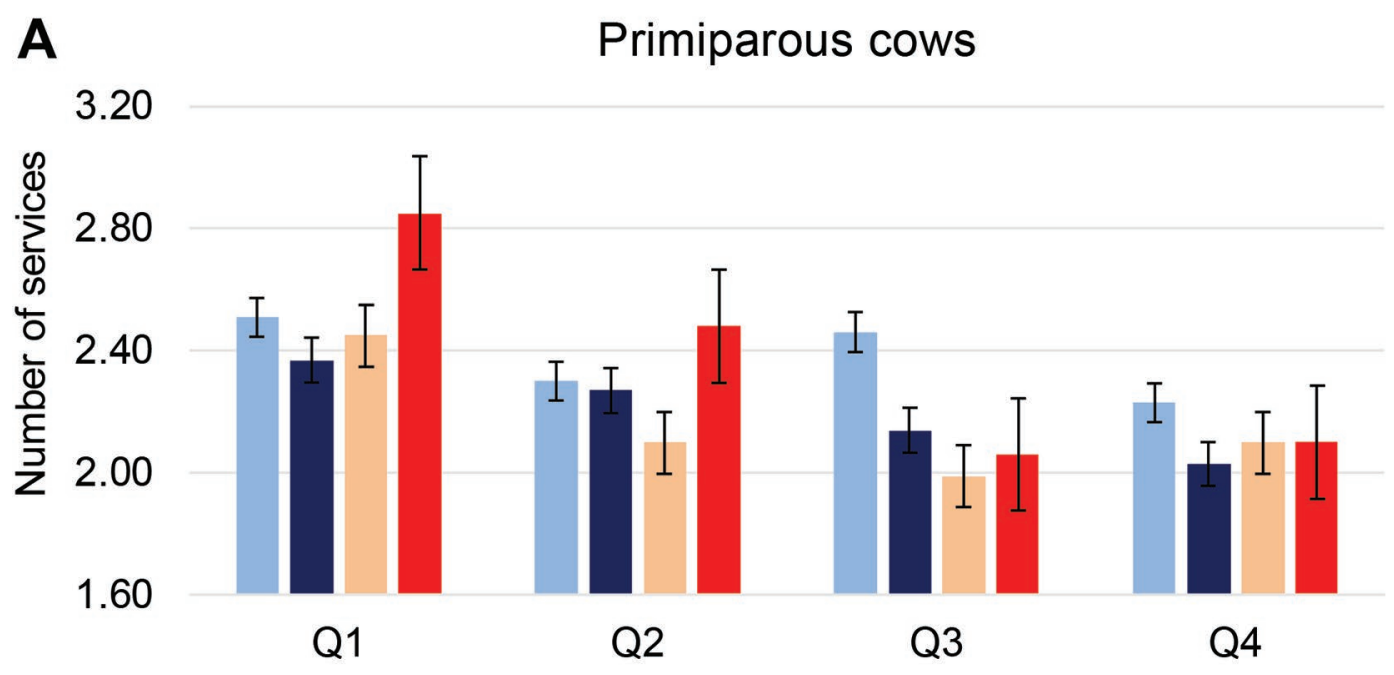

B

\section{Multiparous cows}

2.40

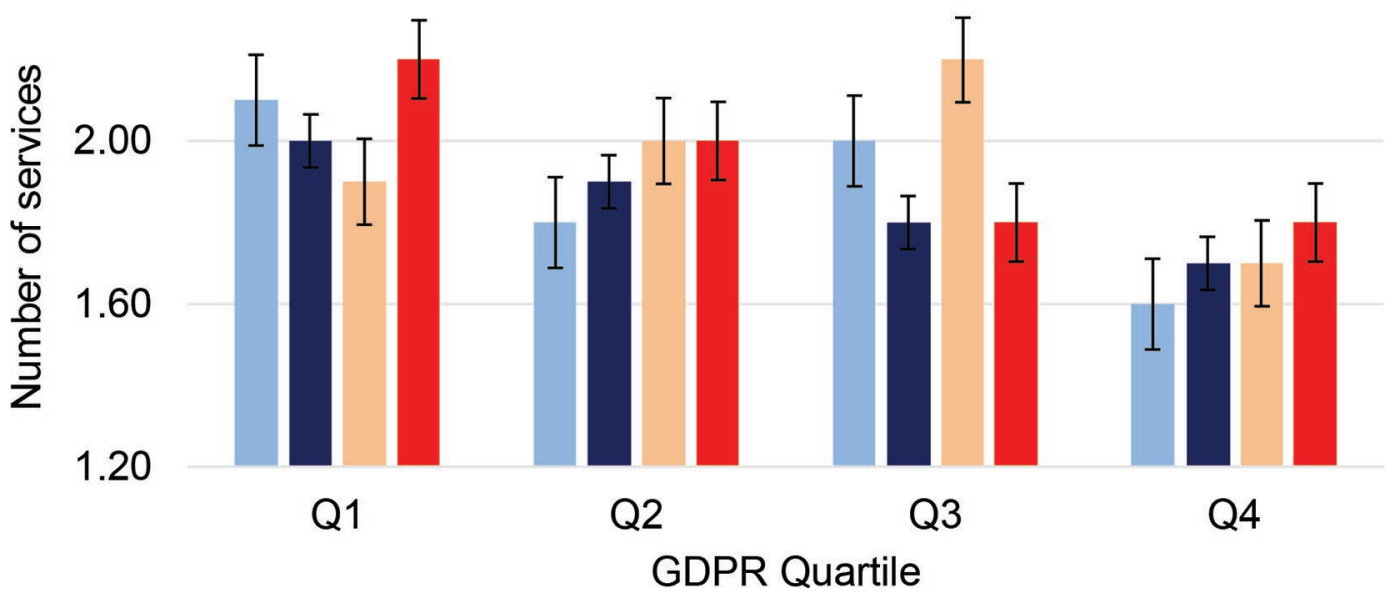

Figure 4. Bar chart displaying the number of services for pregnancy according to quartiles (Q1 = lowest quartile; Q4 = highest quartile) for genomic prediction for daughter pregnancy rate (GDPR) and quartiles for average milk production for the first 2 mo of lactation $(\mathrm{Q} 1=$ lowest quartile; Q4 = highest quartile) in (A) primiparous cows and (B) multiparous cows. Number of services for pregnancy was lower in primiparous $(P<0.001)$ and multiparous $(P<0.001)$ cows in GDRP Q4 than in Q1, Q2, and Q3. The number of services for pregnancy was higher in primiparous $(P<0.001)$ cows in milk quartiles Q1 than in Q2, Q3, and Q4, but no differences for quartiles of milk production in multiparous cows were found. An interaction between GDPR and milk production $(P=0.05)$ was detected for the number of services in primiparous cows, where high-producing cows showed a reduction in number of services as GDPR increased, whereas low-producing cows showed no relationship between GDPR and the number of services. Error bars represent SEM.

et al., 2007) and an increased risk of uterine diseases (Ghavi Hossein-Zadeh and Ardalan, 2011), among others. Future studies are needed to evaluate the relation of GDPR with health traits and metabolism to elucidate potential differences between primiparous and multiparous cows. The poorer reproductive performance of primiparous cows compared with multiparous cows in the current study may be a result of delayed cyclicity and a breeding program that does not specifically benefit primiparous cows with a higher rate of anovulation.

There were positive associations between GDPR and P1, PEND, TPEND, and NSFC, a group of reproductive parameters that is not necessarily totally dependent on estrus detection in herds receiving timed AI, as 
in the current study. Indeed, breeding code (i.e., estrus detection and TAI) was not a significant predictor in our models for first service outcomes. Heifers with high GDPR have larger ovulatory follicles and a tendency to ovulate more when evaluated at $96 \mathrm{~h}$ after the onset of estrus than herdmates with low GDPR (Veronese et al., 2019b). A previous study comparing genetic merit for fertility traits in lactating dairy cows revealed that the cows with high genetic merit had larger ovulatory follicles, greater plasma progesterone concentrations from d 6 to 13 postovulation, and a tendency of increased estradiol at proestrus compared with cows with low genetic merit (Cummins et al., 2012). Other relevant findings include greater concentration of pregnancy-specific protein B from d 28 to 35 post-AI in heifers with high GDPR compared with heifers with low GDPR (Ve-

\section{Milk Production Quartiles \\ $\square \mathrm{Q} 1 \square \mathrm{Q} 2 \backsim \mathrm{Q} 3 \backsim \mathrm{Q} 4$}

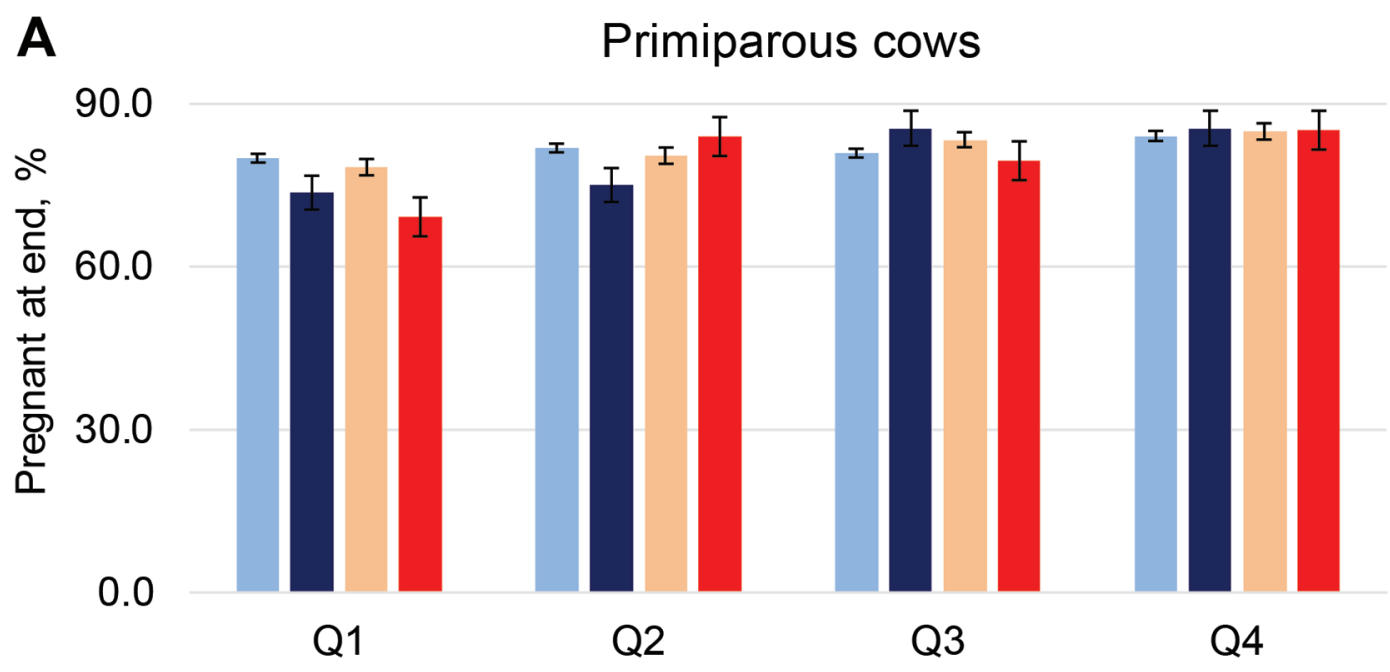

\section{B Multiparous cows}

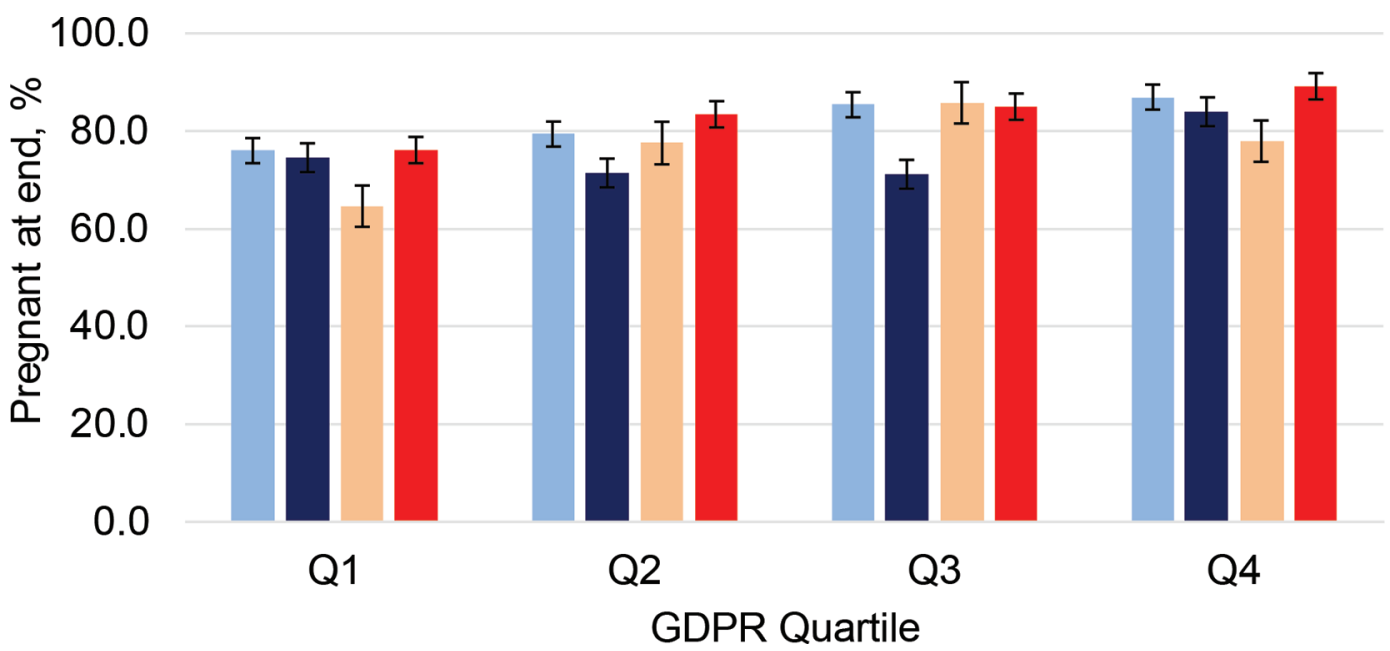

Figure 5. Bar chart displaying the percentage of pregnant cows at the end of lactation according to quartiles (Q1 = lowest quartile; Q4 $=$ highest quartile) for genomic prediction for daughter pregnancy rate (GDPR) and quartiles for 305-d mature-milk equivalent (Q1 = lowest quartile; Q4 = highest quartile) in (A) primiparous cows and (B) multiparous cows. Pregnancy at the end of lactation was greater in primiparous $(P<0.001)$ and multiparous $(P=0.003)$ cows in GDPR Q2, Q3, and Q4 than in Q1, but no differences for quartiles of milk production for primiparous cows and the interactions of GDPR and milk production were found. For multiparous cows, there was also an effect of milk yield $(P=0.03)$, with the lowest quartile $(\mathrm{Q} 1)$ and the highest quartile $(\mathrm{Q} 4)$ having higher pregnancy at the end of lactation than the intermediate quartiles (Q2 and Q3). Error bars represent SEM. 


\section{Milk Production Quartiles}

$\because \mathrm{Q} 1 \backsim \mathrm{Q} 2 \backsim \mathrm{Q} 3 \backsim \mathrm{Q} 4$

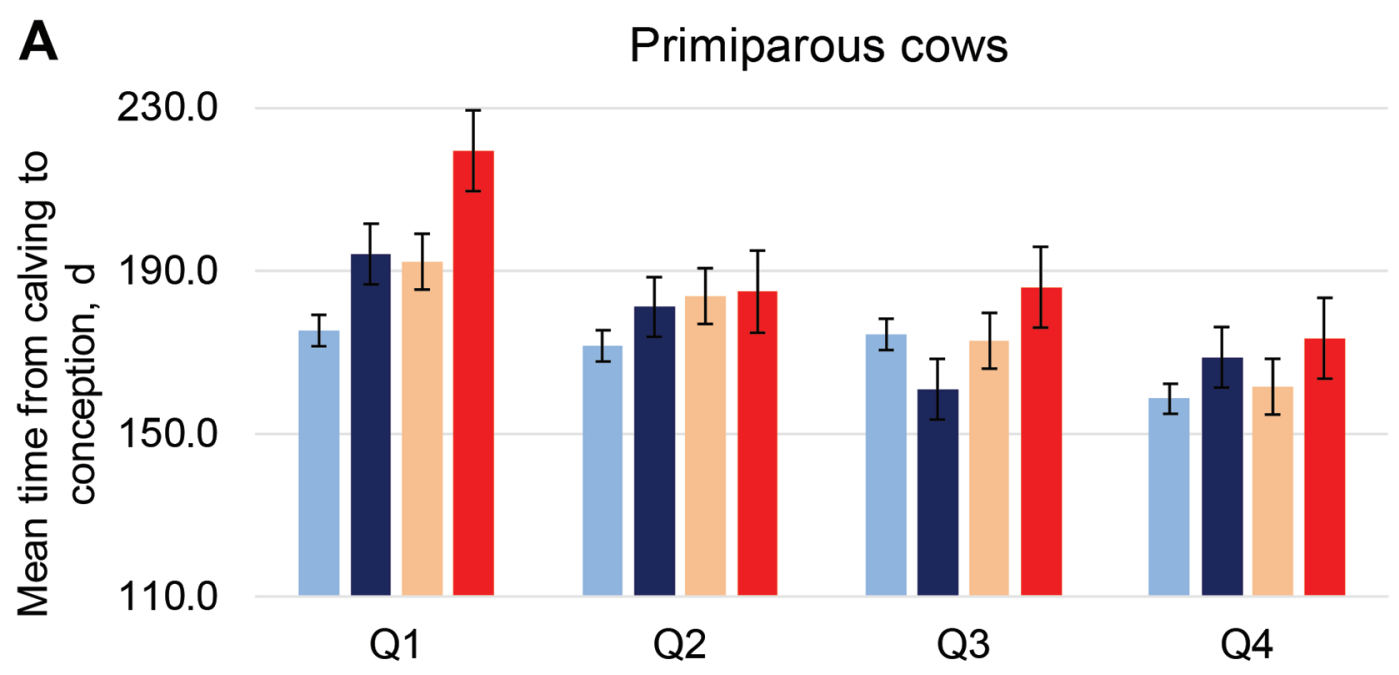

B

Multiparous cows

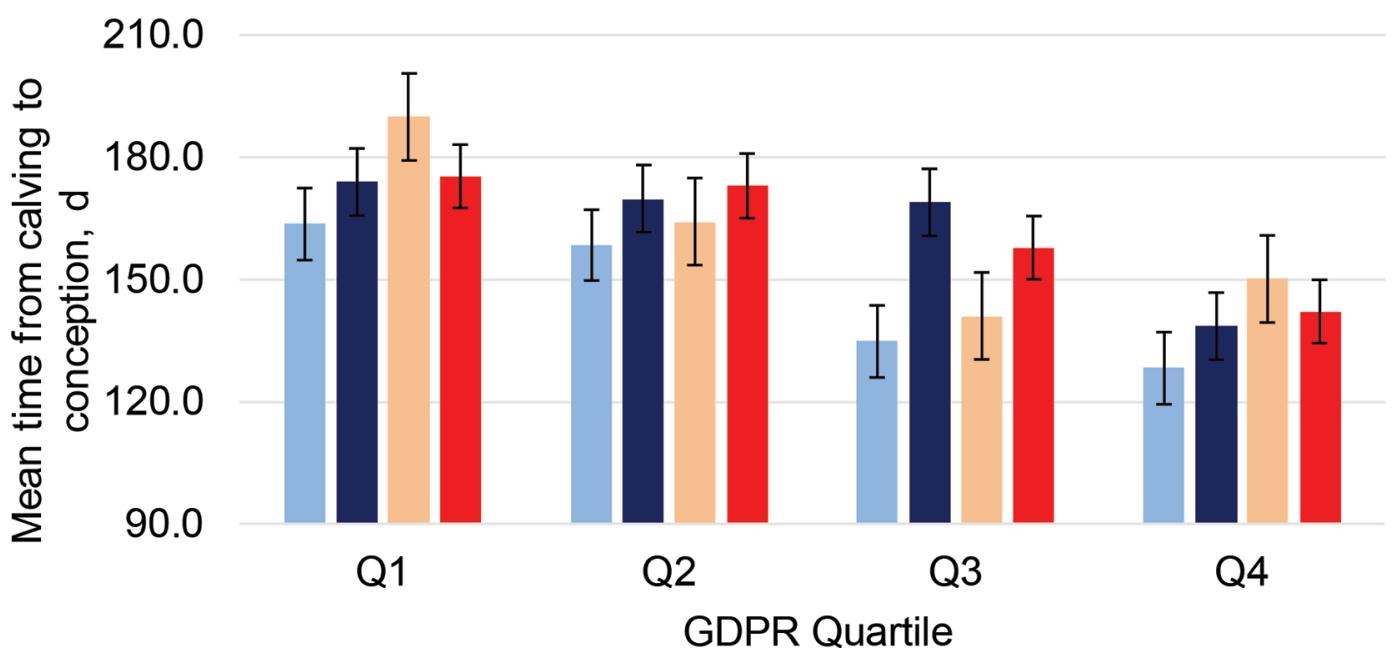

Figure 6. Bar chart displaying the number of days open at the end of lactation according to quartiles $(\mathrm{Q} 1=$ lowest quartile; Q4 $=$ highest quartile) for genomic prediction for daughter pregnancy rate (GDPR) and quartiles for 305-d mature-milk equivalent (Q1 = lowest quartile; Q4 = highest quartile) in (A) primiparous cows and (B) multiparous cows. The number of days open at the end of lactation was greater in primiparous $(P<0.001)$ and multiparous $(P<0.001)$ cows in GDPR quartiles Q2, Q3, and Q4 than in Q1. There was an effect $(P<0.001)$ of milk production, with primiparous cows in Q4 having more days open at the end of lactation than in Q1, Q2, and Q3, whereas multiparous cows in Q2 and Q3 had a tendency for more days open at the end of lactation than cows in Q1 and Q4. No interactions between GDPR and milk production were found. Error bars represent SEM.

ronese et al., 2019b). Indeed, it is a novel finding that pregnancy-specific protein $\mathrm{B}$, which is produced by the conceptus, is associated with the GDPR of the heifer (maternal component). These results indicate that high GDPR, and hence improved fertility, might be mediated by an enhanced dominant follicle and increased plasma levels of estradiol that translate into improved embryo and conceptus development postinsemination.
It is known that a larger corpus luteum reduces early embryonic death in cattle (Lonergan, 2011). Indeed, it has been estimated that 50 to $80 \%$ of bovine embryo losses occur by d 16 of pregnancy (Diskin and Morris, 2008; Wiltbank et al., 2016). Some of these losses have been attributed to luteal phase dysfunction and the downstream effects on histotroph secretion into the uterine lumen (Kimura et al., 1987). 
A significant effect of farm-year-season was found for all reproductive outcomes evaluated in the current study, supporting the idea that fertility is largely controlled by different environmental factors (Berry et al., 2003; Jamrozik et al., 2005; Wall et al., 2005). Environmental factors that can contribute to the variability in reproductive performance include heat stress (season), incidence of postpartum health disorders (Ribeiro et al., 2016), production medicine programs, excessive negative energy balance (Beam and Butler, 1999; Roche et al., 2006), and nutritional or reproductive management programs. Personalized (farm-specific) management systems integrating genomics and highly precise phenotypes are the path for future advancements (Berry et al., 2016).

A highlight of the current study is that the positive effect of GDPR on reproductive performance was independent of milk production for most of the outcomes assessed in multiparous cows and all except number of services in primiparous cows. From an evolutionary perspective, an antagonistic relationship between cows undergoing homeorhetic regulation to support increased milk production for the nourishment of the current calf and subsequent fertility has been suggested (Stearns, 1992; Friggens et al., 2010). A metanalysis revealed that most genetic correlations between production traits (milk yield, fat yield, and protein yield) and a wide range of traditional reproductive traits are unfavorable. However, not all the correlations are negative and some are of small magnitude, suggesting that simultaneous enhancement in genetic merit for fertility and milk production per lactation is possible (Berry et al., 2014). It was suggested that considerable genetic variation exists in reproductive traits to allow simultaneous genetic gain in reproductive performance and milk production in a well-managed farm with a structurally sound breeding program (Berry et al., 2016). Our current findings corroborate that integration of genomic prediction for GDPR helps producers simultaneously select future generations for improved reproduction and milk production, which is a significant forecast that was considered unlikely 20 yr ago.

\section{CONCLUSIONS}

The highest quartile for GDPR was associated with fewer days to first service, greater pregnancy at first service, fewer services to pregnancy, fewer days to pregnancy at the end of lactation, and a greater proportion of pregnant cows at the end of lactation. Significant interactions between milk production and GDPR were not apparent for most of the reproductive traits evaluated. Farm-year-season had a substantial effect on all traits, highlighting the influence that the environment has on dairy cow reproductive performance. The current findings underscore the idea that producers should integrate GDPR as part of the production management program in a manner complementary to milk production to improve both profitability and sustainability of dairy farming.

\section{ACKNOWLEDGMENTS}

The authors thank the owners of the 4 dairy farms in California who kindly agreed to share their data to perform the current study. The authors acknowledge USDA (NIFA AFRI Translational Genomics for Improved Fertility of Animals grant no. 2013-68004) for financial support in this research. The authors have not stated any conflicts of interest.

\section{REFERENCES}

AIPL (Animal Improvement Programs Laboratory). 2005. USDA yield evaluation description. Accessed May 1, 2019. https://aipl.arsusda .gov/reference/yield.htm.

Averill, T. A., R. Rekaya, and K. Weigel. 2004. Genetic analysis of male and female fertility using longitudinal binary data. J. Dairy Sci. 87:3947-3952. https://doi.org/10.3168/jds.S0022-0302(04)73534 -1 .

Beam, S. W., and W. R. Butler. 1999. Effects of energy balance on follicular development and first ovulation in postpartum dairy cows. J. Reprod. Fertil. 54:411-424.

Berry, D. P., F. Buckley, P. Dillon, R. D. Evans, M. Rath, and R. F. Veerkamp. 2003. Genetic relationships among body condition score, body weight, milk yield and fertility in dairy cows. J. Dairy Sci. 86:2193-2204. https://doi.org/10.3168/jds.S0022 -0302(03)73809-0.

Berry, D. P., N. C. Friggens, M. Lucy, and J. R. Roche. 2016. Milk production and fertility in cattle. Annu. Rev. Anim. Biosci. 4:269-290. https://doi.org/10.1146/annurev-animal-021815-111406.

Berry, D. P., E. Wall, and J. E. Pryce. 2014. Genetics and genomics of reproductive performances in dairy and beef cattle. Animal 8(Suppl. 1):105-121. https://doi.org/10.1017/S1751731114000743.

Cummins, S. B., P. Lonergan, A. C. O. Evans, and S. T. Butler. 2012. Genetic merit for fertility traits in Holstein cows: II. Ovarian follicular and corpus luteum dynamics, reproductive hormones, and estrus behavior. J. Dairy Sci. 95:3698-3710. https://doi.org/10 $.3168 /$ jds.2011-4976.

Diskin, M., and D. Morris. 2008. Embryonic and early foetal losses in cattle and other ruminants. Reprod. Domest. Anim. 43:260-267. https://doi.org/10.1111/j.1439-0531.2008.01171.x.

Friggens, N. C., C. Disenhaus, and H. V. Petit. 2010. Nutritional subfertility in the dairy cow: Towards improved reproductive management through a better biological understanding. Animal 4:11971213. https://doi.org/10.1017/S1751731109991601.

García-Ruiz, A., J. B. Cole, P. M. VanRaden, G. R. Wiggans, F. J. Ruiz-López, and C. P. Van Tassell. 2016. Changes in genetic selection differentials and generation intervals in US Holstein dairy cattle as a result of genomic selection. Proc. Natl. Acad. Sci. USA 113:E3995-E4004. https://doi.org/10.1073/pnas.1519061113.

Ghavi Hossein-Zadeh, N., and M. Ardalan. 2011. Cow-specific risk factors for retained placenta, metritis and clinical mastitis in Holstein cows. Vet. Res. Commun. 35:345-354. https://doi.org/10.1007/ s11259-011-9479-5.

Jamrozik, J., J. Fatehi, G. J. Kistemaker, and L. R. Schaeffer. 2005. Estimates of genetic parameters for Canadian Holstein female reproduction traits. J. Dairy Sci. 88:2199-2208. https://doi.org/10 .3168/jds.S0022-0302(05)72895-2. 
Kimura, M., T. Nakao, M. Moriyoshi, and K. Kawata. 1987. Luteal phase deficiency as a possible cause of repeat breeding in dairy cows. Br. Vet. J. 143:560-566. https://doi.org/10.1016/0007 -1935(87)90047-9.

Lonergan, P. 2011. Influence of progesterone on oocyte quality and embryo development in cows. Theriogenology 76:1594-1601. https: //doi.org/10.1016/j.theriogenology.2011.06.012.

Lucy, M. C. 2001. Reproductive loss in high-producing dairy cattle: Where will it end? J. Dairy Sci. 84:1277-1293. https://doi.org/10 .3168/jds.S0022-0302(01)70158-0.

Norman, H. D., J. R. Wright, S. M. Hubbard, R. H. Miller, and J. L. Hutchison. 2009. Reproductive status of Holstein and Jersey cows in the United States. J. Dairy Sci. 92:3517-3528. https://doi.org/ 10.3168/jds.2008-1768.

NRC. 2001. Nutrient Requirements of Dairy Cattle. 7th rev. ed. Natl. Acad. Sci., Washington, DC.

Pryce, J. E., M. D. Royal, P. C. Garnsworthy, and I. L. Mao. 2004. Fertility in the high-producing dairy cow. Livest. Prod. Sci. 86:125-135. https://doi.org/10.1016/S0301-6226(03)00145-3.

Ribeiro, E. S., G. Gomes, L. F. Greco, R. L. A. Cerri, A. Vieira-Neto, P. L. J. Monteiro Jr., F. S. Lima, R. S. Bisinotto, W. W. Thatcher, and J. E. P. Santos. 2016. Carryover effect of postpartum inflammatory diseases on developmental biology and fertility in lactating dairy cows. J. Dairy Sci. 99:2201-2220. https://doi.org/10.3168/ jds.2015-10337.

Roche, J. R., D. P. Berry, and E. S. Kolver. 2006. Holstein-Friesian strain and feed effects on milk production, body weight, and body condition score profiles in grazing dairy cows. J. Dairy Sci. 89:3532-3543. https://doi.org/10.3168/jds.S0022-0302(06)72393 $-1$.

Santos, J. E. P., H. M. Rutigliano, and M. F. Sá Filho. 2009. Risk factors for resumption of postpartum estrous cycles and embryonic survival in lactating dairy cows. Anim. Reprod. Sci. 110:207-221. https://doi.org/10.1016/j.anireprosci.2008.01.014.

Stearns, S. C. 1992. The Evolution of Life Histories. Oxford Univ. Press, Oxford, UK.

USDA. 2019. Daughter pregnancy rate evaluation of cow fertility. Accessed November 25, 2019. https://aipl.arsusda.gov/reference/ fertility/DPR_rpt.htm.

VanRaden, P. M., A. H. Sanders, M. E. Tooker, R. H. Miller, H. D. Norman, M. T. Kuhn, and G. R. Wiggans. 2004. Development of a national genetic evaluation for cow fertility. J. Dairy Sci. 87:22852292. https://doi.org/10.3168/jds.S0022-0302(04)70049-1.

Veronese, A., O. Marques, R. Moreira, A. L. Bellli, R. S. Bisinotto, T. R. Bilby, F. Peñagaricano, and R. C. Chebel. 2019a. Genomic merit for reproductive traits. I: Estrous characteristics and fertility in Holstein heifers. J. Dairy Sci. 102:6224-6238. https://doi.org/10 .3168/jds.2018-15205.

Veronese, A., O. Marques, F. Peñagaricano, R. S. Bisinotto, K. G. Pohler, T. R. Bilby, and R. C. Chebel. 2019b. Genomic merit for reproductive traits. II: Physiological responses of Holstein heifers. J. Dairy Sci. 102:6349-6358. https://doi.org/10.3168/jds.2018 -15245 .

Wall, E., S. Brotherstone, J. F. Kearney, J. A. Woolliams, and M. P. Coffey. 2005. Impact of nonadditive genetic effects in the estimation of breeding values for fertility and correlated traits. J. Dairy Sci. 88:376-385. https://doi.org/10.3168/jds.S0022-0302(05)72697 -7 .

Wathes, D. C., Z. Cheng, N. Bourne, V. J. Taylor, M. P. Coffey, and S. Brotherstone. 2007. Differences between primiparous and multiparous dairy cows in the inter-relationships between metabolic traits, milk yield and body condition score in the periparturient period. Domest. Anim. Endocrinol. 33:203-225. https://doi.org/10.1016/j .domaniend.2006.05.004.

Wiggans, G. R., P. M. VanRaden, and T. A. Cooper. 2011. The genomic evaluation system in the United States: Past, present, future. J. Dairy Sci. 94:3202-3211. https://doi.org/10.3168/jds.2010 $-3866$.

Wiltbank, M. C., G. M. Baez, A. Garcia-Guerra, M. Z. Toledo, P. L. Monteiro, L. F. Melo, J. C. Ochoa, J. E. Santos, and R. Sartori. 2016. Pivotal periods for pregnancy loss during the first trimester of gestation in lactating dairy cows. Theriogenology 86:239-253. https://doi.org/10.1016/j.theriogenology.2016.04.037.

\section{ORCIDS}

F. S. Lima ๑ https://orcid.org/0000-0001-8377-6469

F. Peñagaricano ๑ https://orcid.org/0000-0001-6661-3991

W. W. Thatcher (1) https://orcid.org/0000-0001-6866-3431 